\title{
Differences in the Prevalence of Overweight Between 10-12-Year-old South Asian and Non-South Asian Children in Toronto, Ontario: Findings from Project BEAT
}

\author{
Ananya Tina Banerjee • Parminder K. Flora • \\ Michelle Stone • Guy Faulkner
}

Received: 18 April 2014 / Revised: 27 August 2014 / Accepted: 6 October 2014 /Published online: 23 October 2014

(C) W. Montague Cobb-NMA Health Institute 2014

\begin{abstract}
Objective The objective of this study is to assess the prevalence of overweight among 10-12-year-old South Asian children in comparison to non-South Asian children.

Methods This cross-sectional study obtained data from 16 schools in Toronto, Ontario. The analysis included 734 children (260 South Asian and 475 non-South Asian) aged 10-12 years. Height and weight were measured, and body mass index (BMI; $\mathrm{kg} / \mathrm{m}^{2}$ ) was calculated according to age- and sex-specific cut points established by the International Obesity Task Force (IOTF).

Results The prevalence of overweight was significantly higher among South Asian children when compared to nonSouth Asian children ( 36.9 vs. $23.0 \% ; p<0.001$ ). Unadjusted, South Asian children exhibited increased odds for being overweight $(\mathrm{OR}=1.96 ; \mathrm{CI}=1.41-2.73 ; p<0.001)$ compared to non-South Asian children and persisted after the adjustment for socio-demographic covariates but did not remain significant after the inclusion of physical activity and sedentary behaviour variables. The adjusted odds for being overweight was significantly higher among South Asian boys (but not
\end{abstract}

\footnotetext{
A. T. Banerjee $(\square)$

Women's College Research Institute, Women's College Hospital, Toronto, Ontario, Canada

e-mail: Ananya.Banerjee@wchospital.ca

P. K. Flora

College of Kinesiology, University of Saskatchewan, Saskatoon, Saskatchewan, Canada

M. Stone

School of Health and Human Performance, Dalhousie University,

Halifax, Nova Scotia, Canada

G. Faulkner

Faculty of Kinesiology and Physical Education, University of

Toronto, Toronto, Ontario, Canada
}

girls) compared to their non-South Asian counterparts $(\mathrm{OR}=2.45 ; \mathrm{CI}=1.32-4.55 ; p<0.0001)$.

Conclusions The prevalence of overweight differs by ethnic group and gender. South Asian boys have increased odds of being overweight compared to non-South Asian boys. Children of South Asian origin should receive focused attention in public health initiatives to reduce the risk of becoming overweight and the associated metabolic consequences.

Keywords Child health · Gender · South Asian .

Overweight $\cdot$ Canada

\section{Introduction}

The prevalence of childhood overweight continues to rise in Canada and reports indicate that $30 \%$ of children are overweight or obese [1]. Addressing this major health epidemic is a public health priority given the serious implications of childhood overweight on health and quality of life over a lifespan. Overweight in childhood tracks into adulthood [2] and is associated with adverse outcomes such as cardiovascular disease (CVD), diabetes, hyperlipidemia and hypertension [3].

The available evidence suggests that there is ethnic variation in the prevalence of overweight among children. With respect to South Asian children, studies from the United Kingdom indicate that overweight and obesity is rising significantly among children of this ethnic origin (i.e., those who have ancestral origins from India, Pakistan, Bangladesh and Sri Lanka) [4, 5]. Potential factors contributing to this trend in South Asian children include a higher daily caloric intake, more sedentary behaviour and lower levels of habitual physical activity compared with children of European descent [6].

South Asian adults in Canada are well established as having a higher incidence and prevalence of premature CVD and 
type 2 diabetes [7]. Overweight and obesity is thought to be one of the primary underlying factors in the increased mortality from CVD in people of South Asian origin, and the metabolic effects are apparent from childhood [6, 8]. Therefore, South Asian children could be at greater risk of developing CVD and type 2 diabetes at an earlier stage, and the need to implement prevention strategies including weight control is needed [9].

Despite having a high cardiovascular risk profile in Cana$\mathrm{da}$, there is an absence of representative overweight and obesity data on South Asian children. Because different definitions of body mass index (BMI) are used throughout the world, comparisons of data between countries can be difficult. Further, there are methodological limitations of studies in the UK, including the lack of appropriate socio-demographic (e.g., parental education) and behavioural (e.g., physical activity) adjustments in the statistical models examining odds ratios of childhood overweight and obesity [4, 5]. The lack of appropriate adjustments limits the conclusions that can be drawn from these studies.

The objectives of this study are threefold. First, the prevalence of measured overweight (including obesity) among South Asian children in Canada using age- and sex-specific BMI cut points as defined by the International Obesity Task Force (IOTF) are compared to non-South Asian children. Second, the association between the South Asian ethnicity and childhood overweight is examined after adjusting for several socio-demographic and behavioural covariates, including physical activity measured by accelerometry. Third, the potential moderating effect of gender in the association between the South Asian ethnicity and childhood overweight is assessed.

\section{Methods}

\section{Study Design and Participants}

Data from Project BEAT (Built Environment and Active Transportation; www.beat.utoronto.ca/) were used in this analysis [10]. Project BEAT was a large-scale, multidisciplinary and mixed method study assessing how the built environment influences the way elementary school children travel to school in Toronto, Ontario (Canada). In January 2010, all elementary schools with Grade 5 and 6 students within the Toronto District School Board $(n=469)$ received an invitation to participate. Fifty-four schools responded, 40 of which were interested (response rate $=11$. $5 \%$ ), and 16 schools were selected based on their varying geographic location, socio-economic status (SES) and ethnicity. Neighbourhood classifications were created using the child's home address. Two neighbourhood classifications were created on the basis of the period of neighbourhood development: urban built environment (BE) versus innersuburban BE; two classifications of neighbourhood SES (low SES and high SES) were also created, according to the median household income reported in the 2006 Population Census of Canada [10]. Out of a total of 1704 students enrolled in grades 5 and 6 at the 16 selected schools, 1027 (60.3\%; boys, $n=478$; girls, $n=549)$ obtained parental consent to participate in the study. Prior to any data collection, children completed an assent form $(n=1001 ; 26$ students were absent for data collection). Ethics approval from the Toronto District School Board and University of Toronto Ethics Committee was granted.

\section{Classification by South Asian Ethnicity}

Children of South Asian ethnic origin in the cohort (i.e., those with ethnic origins from India, Pakistan, Sri Lanka and Bangladesh) were classified through a multi-method process by the first author. First, South Asian children were classified from self-reports of a second language spoken at home including Hindi, Urdu, Punjabi, Bengali, Tamil, Telugu, Gujarati, Kannada and Malayalam. These languages are described as the most common and salient aspect of ethnic identity in studies on South Asians [11]. Second, prior to anonymization of the study data, a previously validated protocol of reviewing surnames was used to confirm the classification of South Asian children initially based on reports of speaking a South Asian language at home [12]. This surname list has been shown to have a sensitivity of $50.4 \%$, a specificity of $99.7 \%$ and a positive predictive value of $89.3 \%$ in classifying individuals who previously identified themselves as South Asian from primary data sources [12]. Children having a South Asian surname who reported speaking a South Asian language at home were categorized as South Asian in this study $(n=260)$. The comparison group included children who did not report speaking a second language at home and were categorized as Non-South Asian $(n=474)$. This comparison group represents children with ancestors of European origin (continental Europe, Ireland and United Kingdom). All children who reported speaking a second language not classified as South Asian at home were excluded from the analysis $(n=$ 257), given the diverse range of ethnicities that could not be ascertained, and limited sample sizes to form new ethnicspecific categories.

\section{Measurement of Body Mass Index in Children}

Trained research assistants measured the height and weight of a total of 1001 children at the participating schools. Children's height was measured in centimetres (to the nearest half centimetre), without shoes, using stadiometers. Children's weight was measured in kilograms, to the nearest $100 \mathrm{~g}$ unit 
$(0.1 \mathrm{~kg})$, with normal indoor clothing, without shoes, using mechanical scales (calibrated).

To classify overweight and obesity in young people of 218 years of age, Cole et al. [13, 14], supported by the IOTF, developed a series of age- and sex-specific BMI cut-off points based on data collected from Brazil, UK, Hong Kong, Singapore, the Netherlands and the USA. This present study used these BMI cut-offs that were derived from sex-specific BMI age curves that pass through a BMI of 25 and 30 (the cut-off points used in adults to define overweight and obesity, respectively) at 18 years of age, respectively.

\section{Measurement of Physical Activity}

Physical activity is independently associated with overweight status in children [15] and was controlled for in the current analysis. Children's physical activity was objectively measured for seven days using ActiGraph GT1M ${ }^{\mathrm{TM}}$ accelerometers [16]. As per study requirements, each child wore an accelerometer for a minimum of 10 hours on at least three weekdays and one weekend day [17]. Time spent at various levels of movement intensity was classified according to published thresholds in children [18]. Physical activity variables of interest in this study included minutes of moderate to vigorous physical activity (MVPA) per day and time spent sedentary (minutes per day); physical activity variables are based on an average of physical activity data collected across the week. The distribution of MVPA and sedentary minutes were not normally distributed, therefore, quartiles (bottom; second (median); third; top) and interquartile ranges (IQR) were calculated and categorized.

\section{Socio-demographic Variables}

Potentially confounding socio-demographic factors that were assessed, and shown to be independently associated with weight status in previous work $[15,19,20]$, were also controlled for in the analysis. Demographic and socio-economic questions were asked in the survey administered to parents of all participating children in the BEAT project. Child, parental and school demographics were collected. Child characteristics included age and gender. Parental characteristics included the highest level of education attained by either parent living in the household and was grouped into three categories: (i) high school or less, (ii) university or college and (iii) postgraduate. The socio-economic status (SES) at the school level was classified into two categories: (i) low SES and (ii) high SES. School neighbourhood SES was modelled using median household income and computed at the scale of census dissemination area.

\section{Statistical Analysis}

The prevalence of overweight and obesity was examined in the sample overall and in strata according to ethnic group and gender. Proportions and means for all covariates were computed in the sample overall and in strata according to ethnic group. Pearson chi-square analyses were conducted to compare the distribution of all categorical variables between South Asian and Non-South Asian children. Independent $t$ tests were used to assess for significant differences for continuous variables. Median (interquartile ranges) were calculated for skewed variables (e.g., MVPA and sedentary behaviour). Mann-Whitney tests were used to examine differences in skewed variables.

Three sequential multivariable models were used to assess the impact of potential variables on the association between overweight prevalence and ethnicity. The first model was unadjusted; the second model was adjusted for socio-demographic variables including age, gender and highest level of parental education; the third and 'full' model adjusted for levels of MVPA and sedentary behaviour in addition to the sociodemographic variables. This regression analysis was repeated separately for each gender group to examine the potential moderating effects of gender in predicting overweight in children. All analyses were conducted using SPSS Mac version 21.0.

\section{Results}

The analysis included 734 children 10 to 12 years of age who had valid measures for height and weight. There were 260 (35.4\%) South Asian children classified within this sample. Descriptive characteristics are shown in Table 1. There was no difference in age between South Asian and non-South Asian children. The gender proportion was approximately equal in the group of South Asian children (49.6\% girls vs. $50.4 \%$ boys; $p<0.98$ ), whereas the proportion of girls compared to boys in the group of non-South Asian children was higher (56.8 vs. $43.2 \% ; p<0.01$ ). There were significant differences in the levels of parental education and school SES between the two ethnic groups. South Asian children had higher proportions of either parent having less than or equal to high school education ( 21.7 vs. $7.3 \% ; p<0.05)$ and being enrolled in a low SES neighbourhood school (83.1 vs. $28.9 \% ; p<0.0001)$ in comparison to non-South Asian children.

Comparisons between the groups with respect to physical activity were significantly different. The median MVPA minutes/day was lower (24.1 vs. $28.9 ; p<0.05$ ) in South Asian children compared to non-South Asian children, while the median time spent sedentary (minutes/day) was higher (889.6 vs. $722.7 ; p<0.01$ ).

The overall prevalence of overweight $\left(\mathrm{BMI} \geq 25 \mathrm{~kg} / \mathrm{m}^{2}\right)$ in the total sample of children was $27.9 \%$. Figure 1 shows the 
Table 1 Descriptive characteristics ${ }^{\mathrm{a}}$

\begin{tabular}{|c|c|c|c|c|}
\hline & Overall $(n=734)$ & $\begin{array}{l}\text { South Asian } \\
\text { children }(n=260)\end{array}$ & $\begin{array}{l}\text { Non-South Asian } \\
\text { children }(n=474)\end{array}$ & $p$ value \\
\hline Age, mean (SD), years & $11.1(0.6)$ & $11.0(0.6)$ & $11.1(0.6)$ & 0.98 \\
\hline \multicolumn{5}{|l|}{ Gender, $n(\%)$} \\
\hline Girl & $398(54.1)$ & $129(49.6)$ & $269(56.8)$ & \multirow[t]{2}{*}{0.07} \\
\hline Boy & $336(45.8)$ & $131(50.4)$ & $205(43.2)$ & \\
\hline \multicolumn{5}{|c|}{ Highest level of parental education, $n(\%)$} \\
\hline$\leq$ High school & $89(12.4)$ & $55(21.7)$ & $34(7.3)$ & \multirow[t]{3}{*}{$<0.001$} \\
\hline University or college & $438(60.9)$ & $167(66.0)$ & $271(58.2)$ & \\
\hline Postgraduate & $192(26.7)$ & $31(12.3)$ & $161(34.5)$ & \\
\hline \multicolumn{5}{|l|}{ School socio-economic status, $n(\%)$} \\
\hline Low & $353(48.1)$ & $216(83.1)$ & $137(28.9)$ & \multirow[t]{2}{*}{$<0.0001$} \\
\hline High & $381(51.9)$ & $44(16.9)$ & $337(71.1)$ & \\
\hline \multicolumn{5}{|l|}{ Physical activity, median (IQR) } \\
\hline MVPA minutes/day & $27.0(19.2-37.7)$ & $24.1(17.9-34.4)$ & $28.9(21.0-38.6)$ & \multirow[t]{2}{*}{$<0.001$} \\
\hline Time spent sedentary minutes/day & $800.3(621.8-969.2)$ & $889.6(662.1-991.3)$ & $722.7(608.3-947.9)$ & \\
\hline Height, mean $(\mathrm{SD}) \mathrm{cm}$ & $147.3(8.6)$ & $146.4(9.8)$ & $147.8(7.8)$ & \multirow[t]{2}{*}{$<0.05$} \\
\hline Weight, mean (SD), kg & $41.4(10.0)$ & $42.4(10.3)$ & $40.8(9.9)$ & \\
\hline \multicolumn{5}{|l|}{ Weight status ${ }^{\mathrm{b}}, n(\%)$} \\
\hline Normal weight & $529(72.1)$ & $164(63.1)$ & $365(77.0)$ & \multirow[t]{3}{*}{$<0.001$} \\
\hline Overweight & $148(20.2)$ & $67(25.8)$ & $81(17.1)$ & \\
\hline Obese & $57(7.7)$ & $29(11.1)$ & $28(5.9)$ & \\
\hline
\end{tabular}

Percentages may not add up to 100 due to missing data

MVPA moderate to vigorous physical activity, IQR interquartile range, BMI body mass index, IOTF International Obesity Task Force

${ }^{a}$ Median (IQRs) are given for skewed variables. Mann-Whitney tests were used to examine differences in skewed variables; $X^{2}$ tests were used to examine differences in percentages; independent $t$ tests were used to examine differences in means

${ }^{\mathrm{b}}$ Weight status categories were established using BMI age- and sex-specific IOTF thresholds [14]

prevalence of overweight was significantly higher among South Asian children when compared to non-South Asian children (36.9 vs. $23.0 \% ; p<0.001)$. The results of the logistic regression analyses predicting overweight in South Asian children are presented in Table 2. Unadjusted (Model 1), South Asian children exhibited increased odds for being overweight $(\mathrm{OR}=1.96 ; \mathrm{CI}=1.41-2.73 ; p<0.0001)$ and persisted after the adjustment for socio-demographic covariates (Model 2). However, these results did not remain significant after the

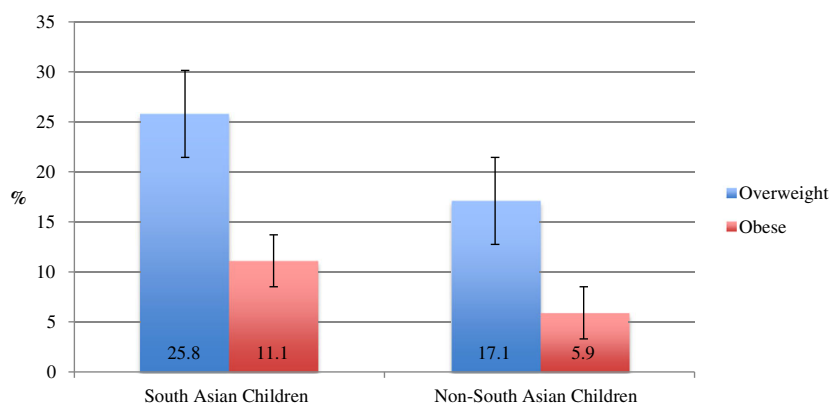

Fig. 1 Prevalence of overweight and obesity in South Asian and NonSouth Asian children inclusion of physical activity and sedentary behaviour variables (Model 3).

The prevalence of overweight children was significantly higher among South Asian boys in comparison to non-South Asian boys (42.7 vs. $22.4 \%$; $p<0.0001)$. South Asian girls also had a higher prevalence of overweight compared to nonSouth Asian girls (31.0 vs. $23.4 \% ; p<0.001)$. Table 3 shows the unadjusted and adjusted odds ratio for overweight separately for South Asian boys and girls. After the adjustment for socio-demographic and behavioural covariates (Model 3A), the odds for being overweight was significantly higher among South Asian boys compared with their non-South Asian counterparts $(\mathrm{OR}=2.45 ; \mathrm{CI}=1.32-4.55 ; p<0.0001)$. However, the unadjusted (Model 1B) and adjusted odds (Models 2B and 3B) for being overweight among South Asian girls was nonsignificant when compared to non-South Asian girls.

\section{Discussion}

This paper provides evidence that there is ethnic variation in the prevalence of overweight based on IOTF criteria. The 
Table 2 Unadjusted and adjusted odds ratio for overweight among South Asian children from 10 to 12 years of age

\begin{tabular}{|c|c|c|c|}
\hline & $\begin{array}{l}\text { Model } 1 \\
\text { unadjusted } \\
\text { OR } 95 \% \text { CI }\end{array}$ & $\begin{array}{l}\text { Model } 2 \\
\text { adjusted } \\
\text { OR } 95 \% \text { CI }\end{array}$ & $\begin{array}{l}\text { Model } 3 \\
\text { adjusted } \\
\text { OR } 95 \% \text { CI }\end{array}$ \\
\hline \multicolumn{4}{|l|}{ Ethnicity } \\
\hline $\begin{array}{l}\text { Non-South } \\
\text { Asian }\end{array}$ & 1.0 & 1.0 & 1.0 \\
\hline South Asian & $1.96(1.41-2.73)^{*}$ & $1.52(1.01-2.17)^{* *}$ & $1.32(0.87-2.01)$ \\
\hline \multicolumn{4}{|l|}{ Gender } \\
\hline Boy & & 1.0 & 1.0 \\
\hline Girl & & $0.84(0.60-1.17)$ & $0.53(0.35-0.81)^{* *}$ \\
\hline Age & & $0.81(0.61-1.07)$ & $0.84(0.62-1.15)$ \\
\hline \multicolumn{4}{|c|}{ Highest level of parental education } \\
\hline$\leq$ High school & & 1.0 & 1.0 \\
\hline $\begin{array}{l}\text { University or } \\
\text { college }\end{array}$ & & $0.80(0.50-1.31)$ & $0.73(0.43-1.24)$ \\
\hline Postgraduate & & $0.40(0.23-0.73)^{* *}$ & $0.32(0.16-0.62)^{* *}$ \\
\hline \multicolumn{4}{|c|}{ MVPA (quartile no.) (minutes per day) } \\
\hline Bottom & & & 1.0 \\
\hline Second & & & $0.36(0.21-0.61)^{*}$ \\
\hline Third & & & $0.45(0.27-0.77)^{*}$ \\
\hline Top & & & $0.18(0.10-0.34)^{*}$ \\
\hline \multicolumn{4}{|c|}{ Time spent sedentary (quartile no.) (minutes per day) } \\
\hline Bottom & & & 1.0 \\
\hline Second & & & $1.24(0.71-2.15)$ \\
\hline Third & & & $0.90(0.50-1.62)$ \\
\hline Top & & & $0.73(0.39-1.34)$ \\
\hline
\end{tabular}

For MVPA minutes per day, the bottom quartile represents all comparisons up to $19.1 \mathrm{~min}$ per day (reference category), the second quartile represents 19.2 to $26.9 \mathrm{~min}$ per day, the third quartile represents 27.0 to $37.6 \mathrm{~min}$ per day and the top quartile represents $37.7 \mathrm{~min}$ or more per day For time spent sedentary (minutes per day), the bottom quartile represents all comparisons up to $621.7 \mathrm{~min}$ per day (reference category), the second quartile represents 621.8 to $800.2 \mathrm{~min}$ per day, the third quartile represents 800.3 to $969.2 \mathrm{~min}$ per day and the top quartile represents $969.3 \mathrm{~min}$ or more per day

Models 2 and 3 are adjusted for clustering effects of schools (data not shown)

OR odds ratio, $M V P A$ moderate to vigorous physical activity

${ }^{*} p<0.001 ; * * p<0.05$

results indicate a higher prevalence of overweight among South Asian children living in Canada (36.9 vs. $23.0 \%$ ). These findings are consistent with past studies reported in the literature on overweight and obesity in children of South Asian origin [4-6]. The current findings provide further insight about the relationship between overweight and ethnicity by controlling for demographic and behavioural factors, which are infrequently considered in the extant literature. Based on this important statistical and methodological consideration, we found that when examining the overall sample of children, after controlling for some known correlates of overweight (i.e., age, gender, highest level of parental education, physical activity and time spent sedentary), the associations between ethnicity and overweight prevalence that were previously observed were no longer significant.

Notably, when examining gender groups separately, we found that among girls, initially significant associations between ethnicity and gender were ultimately found to be nonsignificant after controlling for covariates, whereas among boys, the association remained significant. This finding suggests that gender is an important consideration when examining the association between overweight and ethnicity among children of South Asian origin. The study highlights that South Asian boys had approximately three times the likelihood of being overweight compared to non-South Asian boys when relevant socio-demographic and behavioural factors were taken into account. Interactions between gender and ethnicity for overweight and obesity have been similarly shown in previous work, indicating a moderating effect [4, 5]. Saxena et al. [5] found that Indian $(\mathrm{OR}=1.55 ; 95 \% \mathrm{CI}$ 1.12-2.17) and Pakistani (OR=1.36; $95 \%$ CI 1.01-1.83) boys were more likely to be overweight than children in the general population living in the United Kingdom. Further, Balakrishnan et al. [4] showed the odds of being overweight $(\mathrm{OR}=1.77 ; 95 \%$ CI $1.56-2.00 ; p<0.05)$ and obese $(\mathrm{OR}=$ $1.76 ; 95 \%$ CI 1.50-2.06; $p<0.05$ ) were significantly higher among South Asian boys compared to White children. Saxena et al. attribute these gender-specific findings to explicit ideals of body morphology around critical stages in child development and peri-pubertal development of boys within the South Asian culture [5]. Further, the literature indicates there is a perceived cultural norm within the U.K. South Asian population that is overweight is acceptable, even ideal in male children [21]. Therefore, the finding that South Asian boys are more likely to be overweight, and that this may be considered a cultural norm, is a potential public health concern.

Our study examined and adjusted for ethnic differences in physical activity and sedentary behaviour, which both could be important correlates of the higher prevalence of overweight among South Asian children. Previous studies of similar analyses have not adjusted for these confounding factors that might partially explain the ethnic differences in overweight prevalence. Low levels of physical activity and increased sedentary behaviour are known to be prevalent in minority ethnic groups, in particular, those of South Asian origin in Canada $[22,23]$. Overall, the study sample did not meet the Canadian Physical Activity Guidelines for children, which outline that children should accumulate at least $60 \mathrm{~min}$ of MVPA daily. The difference in the median (interquartile range) minutes of objectively measured MVPA per day was minimal between the two groups of children. However, South Asian children spent markedly more time engaged in sedentary behaviour than non-South Asian children in this study. The importance of this pattern is of concern in South Asian children, since high levels of sedentary behaviour have been 
Table 3 Unadjusted and adjusted odds ratio for overweight in South Asian from 10 to 12 years of age children by gender

\begin{tabular}{|c|c|c|c|c|c|c|}
\hline & \multicolumn{3}{|l|}{ Boys } & \multicolumn{3}{|l|}{ Girls } \\
\hline & $\begin{array}{l}\text { Model 1A } \\
\text { unadjusted } \\
\text { OR } 95 \% \text { CI }\end{array}$ & $\begin{array}{l}\text { Model 2A } \\
\text { adjusted }^{\mathrm{a}} \\
\text { OR } 95 \% \text { CI }\end{array}$ & $\begin{array}{l}\text { Model 3A } \\
\text { adjusted }^{\mathrm{b}} \\
\text { OR } 95 \% \text { CI }\end{array}$ & $\begin{array}{l}\text { Model 1B } \\
\text { unadjusted } \\
\text { OR } 95 \% \text { CI }\end{array}$ & $\begin{array}{l}\text { Model 2B } \\
\text { adjusted }^{\mathrm{a}} \\
\text { OR } 95 \% \text { CI }\end{array}$ & $\begin{array}{l}\text { Model 3B } \\
\text { adjusted }^{\mathrm{b}} \\
\text { OR } 95 \% \text { CI }\end{array}$ \\
\hline \multicolumn{7}{|l|}{ Ethnicity } \\
\hline Non-South Asian & 1.0 & 1.0 & 1.0 & 1.0 & 1.0 & 1.0 \\
\hline South Asian & $2.58(1.60-4.16)^{*}$ & $2.26(1.35-3.78)^{*}$ & $2.45(1.32-4.55)^{*}$ & $1.47(0.92-2.35)$ & $1.11(0.67-1.85)$ & $0.92(0.51-1.66)$ \\
\hline
\end{tabular}

OR odds ratio, $M V P A$ moderate to vigorous physical activity

${ }^{\text {a }}$ Adjusted for age, parental education, cluster of schools

${ }^{\mathrm{b}}$ Adjusted for variables in Model 2 and MVPA and time spent sedentary (minutes/day)

${ }^{*} p<0.0001$

shown to increase the risk of overweight and related health problems, including type 2 diabetes, CVD and various metabolic factors [24]. Focused health promotion efforts should target South Asian children in encouraging less sedentary time and greater physical activity, in part to address overweightrelated health problems.

South Asian adults in Canada have an elevated risk of CHD compared to the general population and have marked insulin resistance and central obesity [7, 25]. The findings of this study may suggest that these differences in disease risk are emerging before adult life. Currently, South Asian children, especially boys in Canada, show evidence of excess overweight and obesity from 10 years of age. This adverse risk factor could have an important contribution to the development of metabolic abnormalities in South Asian children that persist into adulthood [26]. Our findings are in line with emerging evidence indicating cardiometabolic risk is high in South Asian children with higher levels of excess weight and insulin resistance [6].

There are strengths and limitations of the study. This report is among the first studies examining ethnic group differences in overweight children living in Canada. The study strengths are its use of objective measures (BMI, physical activity, sedentary behaviour), which is an important consideration given the limitations of self-report, such as biases and problems associated with recall in children. Employing multivariate statistical analytical techniques that allowed important correlates of overweight to be considered is an important strength of the study, which addresses potential confounding factors. The use of BMI cut points outlined by the IOTF offers standardized values with which to define overweight [14]. However, although BMI acts as a proxy for both lean and fat mass, it does not reflect body composition. Accordingly, one limitation of this study is that identified valid and reliable indices of overweight and obesity, such as waist and hip circumference and subcutaneous fat measurement, were not employed.

Studies show that South Asian populations are at an increased risk of cardiometabolic disorders at lower BMI levels compared to the general population, which has been attributed to considerably higher body fat percentage [27]. For this reason, the World Health Organization (WHO) recommend lowering the BMI cut-offs for South Asian adults, for overweight from 25 to $23 \mathrm{~kg} / \mathrm{m}^{2}$ and for obesity from 30 to $27.5 \mathrm{~kg} / \mathrm{m}^{2}$, due to the increased health risks [28]. Lowered BMI cut-offs to determine overweight and obesity in South Asian children have been proposed but have yet to be adopted by the WHO or IOTF [29]. If the proposed BMI criteria for South Asian children are considered, the prevalence of overweight and obesity in South Asian children is likely to be underestimated in this study.

The multivariate models in this study predicting overweight prevalence in South Asian children did not account for total energy intake. Differences in overweight prevalence between South Asian children and non-South Asian children may be partially explained by total energy intake. In the U.K., South Asian children reported higher mean total energy intake compared with White Europeans [30]. However, this limitation is counterbalanced by the objective measures of physical activity and time spent sedentary, which is consistently correlated with energy intake in children; lack of energy intake measurement is unlikely to have changed the study findings significantly [31]. Future studies should consider total energy intake as a factor when examining overweight and ethnicity.

Parental immigration status is an important sociodemographic factor that was not collected in the study and could not be adjusted for in the multivariate models predicting overweight prevalence. There is marked variation in cardiovascular risk factors (including overweight and obesity) by the immigrant status (recent vs. long term) of South Asian adults living in Canada [7]. Studies suggest the process of adjustment to Canadian lifestyle norms may be driving excess weight gain with additional years in Canada among immigrant South Asian adults and children [32]. Factors associated with immigration should be considered in future studies.

Additionally, the purpose of the BEAT study was not to collect data on a representative sample of children. The focus 
was on sampling based on differences in socio-economic status of neigbourhoods and their historic development in order to explore variations in school travel. Therefore, the results of the present study may not be generalizable to other South Asian populations in Ontario or elsewhere. Further, using self-reports of a second language spoken at home and surname lists to assign the South Asian and non-South Asian ethnicity could lead to misclassification of children whose surnames do not reflect their ethnicity, such as those of mixed ethnicity.

In conclusion, the explanation for the observed ethnic variation in overweight prevalence is uncertain but is likely multifactorial. Further research is required to better identify those aspects of physical activity that are most predictive of overweight among South Asian children. Ideally, studies that employ a longitudinal design should be used to examine the predictors of weight gain, overweight and obesity in this ethnic population of children. Given that people of South Asian origin are more sensitive to the metabolic consequences of overweight and obesity, the prevention of obesity in childhood and adolescence among South Asian people, with a combination of dietary measures and increased physical activity, should be a public health priority in Canada.

Acknowledgments This research was funded by the Built Environment, Obesity and Health Strategic Initiative of the Heart and Stroke Foundation and the Canadian Institutes of Health Research (CIHR). Dr. Banerjee is supported by a CIHR Postdoctoral Fellowship Award. The authors would like to thank paediatrician Dr. Prateek Lala MD FRCPC for reviewing the manuscript for important intellect content.

Conflicts of Interest $\quad$ Dr. Banerjee, Dr. Flora, Dr. Stone and Dr. Faulkner declare that they have no conflict of interest.

Informed Consent All procedures followed were in accordance with the ethical standards of the responsible committee on human experimentation (institutional and national) and with the Helsinki Declaration of 1975, as revised in 2000. Informed consent was obtained from all parents of the participants for being included in the study. Children also provided assent.

\section{References}

1. Tremblay MS, Katzmarzyk PT, Willms JD. Temporal trends in overweight and obesity in Canada, 1981-1996. Int J Obes Relat Metab Disord. 2002;26(4):538-43.

2. Singh AS, Mulder C, Twisk JW, van Mechelen W, Chinapaw MJ. Tracking of childhood overweight into adulthood: a systematic review of the literature. Obes Rev. 2008;9(5):474-88.

3. Ball GD, McCargar LJ. Childhood obesity in Canada: a review of prevalence estimates and risk factors for cardiovascular diseases and type 2 diabetes. Can J Appl Physiol. 2003;28(1):117-40.

4. Balakrishnan R, Webster P, Sinclair D. Trends in overweight and obesity among 5-7-year-old White and South Asian children born between 1991 and 1999. J Public Health (Oxf). 2008;30(2):139-44.
5. Saxena S, Ambler G, Cole TJ, Majeed A. Ethnic group differences in overweight and obese children and young people in England: cross sectional survey. Arch Dis Child. 2004;89(1):30-6.

6. Owen CG, Nightingale CM, Rudnicka AR, et al. Physical activity, obesity and cardiometabolic risk factors in 9- to 10-year-old UK children of white European, South Asian and black AfricanCaribbean origin: the Child Heart And health Study in England (CHASE). Diabetologia. 2010;53(8):1620-30.

7. Chiu M, Austin PC, Manuel DG, Tu JV. Cardiovascular risk factor profiles of recent immigrants vs long-term residents of Ontario: a multi-ethnic study. Can J Cardiol. 2012;28(1):20-6.

8. Vuksan V, Rogovik A, Jenkins A, et al. Cardiovascular risk factors, diet and lifestyle among European, South Asian and Chinese adolescents in Canada. Paediatr Child Health. 2012;17(1):e1-6.

9. Pallan M, Parry J, Adab P. Contextual influences on the development of obesity in children: a case study of UK South Asian communities. Prev Med. 2012;54(3-4):205-11.

10. Stone MR, Faulkner GE, Mitra R, Buliung R. Physical activity patterns of children in Toronto: the relative role of neighbourhood type and socio-economic status. Can J Public Health. 2012;103(9 Suppl 3):eS9-eS14.

11. Laroche M, Pons F, Richard MO. The role of language in ethnic identity measurement: a multitrait-multimethod approach to construct validation. J Soc Psychol. 2009;149(4):513-39.

12. Shah BR, Chiu M, Amin S, Ramani M, Sadry S, Tu JV. Surname lists to identify South Asian and Chinese ethnicity from secondary data in Ontario, Canada: a validation study. BMC Med Res Methodol. 2010;10:42.

13. Cole TJ, Bellizzi MC, Flegal KM, Dietz WH. Establishing a standard definition for child overweight and obesity worldwide: international survey. BMJ. 2000;320(7244):1240-3.

14. Cole TJ, Lobstein T. Extended international (IOTF) body mass index cut-offs for thinness, overweight and obesity. Pediatr Obes. 2012;7(4):284-94.

15. Must A, Tybor DJ. Physical activity and sedentary behavior: a review of longitudinal studies of weight and adiposity in youth. Int J Obes (Lond). 2005;29 Suppl 2:S84-96.

16. [computer program]. Version. Pensacola, FL United States: ActiGraph LLC.

17. Stone MR, Rowlands AV, Eston RG. Characteristics of the activity pattern in normal weight and overweight boys. Prev Med. 2009;49(2-3):205-8.

18. Stone MR, Rowlands AV, Middlebrooke AR, Jawis MN, Eston RG. The pattern of physical activity in relation to health outcomes in boys. Int J Pediatr Obes. 2009;4(4):306-15.

19. Reilly JJ, Armstrong J, Dorosty AR, et al. Early life risk factors for obesity in childhood: cohort study. BMJ. 2005;330(7504):1357.

20. Ness AR, Leary S, Reilly J, et al. The social patterning of fat and lean mass in a contemporary cohort of children. Int $\mathrm{J}$ Pediatr Obes. 2006;1(1):59-61.

21. Hill AJ, Bhatti R. Body shape perception and dieting in preadolescent British Asian girls: links with eating disorders. Int J Eat Disord. 1995;17(2):175-83.

22. Bryan SN, Tremblay MS, Perez CE, Ardern CI, Katzmarzyk PT. Physical activity and ethnicity: evidence from the Canadian Community Health Survey. Can J Public Health. 2006;97(4):271-6.

23. Dogra S, Meisner BA, Ardern CI. Variation in mode of physical activity by ethnicity and time since immigration: a cross-sectional analysis. Int J Behav Nutr Phys Act. 2010;7:75.

24. Cook S, Auinger P, Li C, Ford ES. Metabolic syndrome rates in United States adolescents, from the National Health and Nutrition Examination Survey, 1999-2002. J Pediatr. 2008;152(2):165-70.

25. Anand SS, Yusuf S, Vuksan V, et al. Differences in risk factors, atherosclerosis and cardiovascular disease between ethnic groups in Canada: the study of health assessment and risk in ethnic groups (SHARE). Indian Heart J. 2000;52(7 Suppl):S35-43. 
26. Bao W, Srinivasan SR, Wattigney WA, Berenson GS. The relation of parental cardiovascular disease to risk factors in children and young adults. The Bogalusa Heart Study. Circulation. 1995;91(2):365-71.

27. Deurenberg-Yap M, Chew SK, Lin VF, Tan BY, van Staveren WA, Deurenberg P. Relationships between indices of obesity and its comorbidities in multi-ethnic Singapore. Int J Obes Relat Metab Disord. 2001;25(10):1554-62.

28. WHO expert consultation. Appropriate body-mass index for Asian populations and its implications for policy and intervention strategies. Lancet. 2004;363(9403):157-63.

29. de Wilde JA, Zandbergen-Harlaar S, van Buuren S, Middelkoop BJ. Trends in body mass index distribution and prevalence of thinness, overweight and obesity in two cohorts of Surinamese South Asian children in The Netherlands. Arch Dis Child. 2013;98(4):280-5.

30. Donin AS, Nightingale CM, Owen CG, et al. Nutritional composition of the diets of South Asian, black African-Caribbean and white European children in the United Kingdom: the Child Heart and Health Study in England (CHASE). Br J Nutr. 2010;104(2):276-85.

31. Sallis JF, Prochaska JJ, Taylor WC. A review of correlates of physical activity of children and adolescents. Med Sci Sports Exerc. 2000;32(5):963-75.

32. McDonald JT, Kennedy S. Is migration to Canada associated with unhealthy weight gain? Overweight and obesity among Canada's immigrants. Soc Sci Med. 2005;61(12):2469-81. 